\title{
THE STATE DENTAL SOCIETY AS AN IMPORTANT LEGISLATIVE FACTOR.
}

\author{
By Homer C. Brown, D. D. S., Columbus, Ohio.
}

(Read before the National Dental Association at Its Twentieth Annual Session, Louisvile, Ky., July 25-28, 1916.)

$\mathrm{T}$ HE State Dental Society is the second as well as a most essential unit in our present plan of organization. Its favored pivotal position makes its influence far reaching and in both directions. In fact, it very largely directs the activities and regulates the policies of its component societies which, in the final analysis, represents the interests of the best element of the profession within the state. It should also receive and harmonize the different suggestions or recommendations of the profession within the state to the end that the views of its members, thru their delegates, are given full consideration in determining and outlining the policies of the National Dental Association.

As a legislative factor, the State Society's position is such as to wield a very positive influence for whatever may improve conditions within the state, as wéll as to render material assistance in support of approved and advocated Federal legislation. This need not necessarily be restricted to only those questions effecting dentistry, but can be very properly applied to any meritorious proposal having for its purpose the improvement of conditions for humanity in any specific or general way, and especially when it is related, either directly or indirectly, to our profession. For instance, any legislation which tends to promote better health and educational standards is a subject in which our profession can very properly become interested, since no one, in this present day of enlightment, can question the direct relation of these two subjects to dentistry.

With these preliminary statements, and in order to best serve the purposes as contemplated in this paper, legislation may very properly be discussed under three classifications, as follows:

First-That legislation which has to do with the municipality and which comes within the jurisdiction of Council, Board of Alderman or some other elected officials with similar prescribed duties.

Second-That legislation which is a matter of state concern and comes within the jurisdiction of the State Legisla. ture.

Third-That legislation which affects alike all states, and similar subdivisions of the United States and which comes within the jurisdiction of Congress.

It is regretted that under the first classification the dentist very seldom takes any appreciable interest in distinctive and important local questions, not even as much as would seem best for the advancement of our profession or the development of a broader view for the individual. This is unfortunate and does not tend to keep our profession in the line of progress. with other professions and vocations. Further, this lack of interest refiects its detrimental influence in many directions while the reverse will have an equally stimulating 
effect for good for both the individual and the profession. Whatever makes a dentist a more useful citizen to his community has a more or less direct relation upon our professional progress in general.

Under the second classification most of our attention in the past has been directed toward the securing of state laws regulating the practice of dentistry. This was and is very creditable work, but again I say it is unfortunate that the State Dental Society, from a legislative point of view, does not assume a broader and more generally useful policy. For that reason we have been criticized for being entirely selfish in the legislation we were advocating. Therefore, it would seem that the dentists, as individuals, as well as thru our organizations, should broaden their views, as it were, and take cognizance of some of the important questions confronting our various legislative bodies. In this manner we can at least partially remove the criticism that some have been disposed to make relative to our limited interest.

The third classification brings us io the United States Congress. This enlarges our field of usefulness but at the same time we are more or less handicapped at the outset because of a number of reasons, some of which I will enumerate as follows:

(1) The enormous amount of proposed legislation.

(2) The necessity for giving full consideration to the big and necessary bills.

(3) The varied interests and views regarding any particular subject.

(4) The lack of time required to secure final action upon any measure which is not generally recognized as important or which is in some way connected with necessary legislation.

(5) The great distance of the Capitol from most of the states.

(6) The necessary time and expense involved in order to secure final and satisfactory results.
Thus, in view of the above, it requires additional effort to overcome these obstacles and in doing this the strongest factor must necessarily be a concerted effort in support of an approved policy. In this connection nothing is so essential and dependable as the state organizations. Their positions are favorable for impressing the members of Congress with the importance of what seems to them to be just and equitable legislation. Let it be understood that any proposed legislation should first be fully studied, carefully prepared and generally approved. Just at this point in my dictation I am prompted to incorporate a message reaching me at this moment from one of our Vice-Presidents as follows: "Sent twenty telegrams from Detroit dentists to our Senators. Hope it will do some good." This was in response to a request to reach their senators in behalf of pending Navy legislation and I am quite sure that those Senators are going to appreciate the fact that their constituents are deeply interested in the legislation referred to and they thus will be prompted to give it more favorable consideration than they would under other conditions, that is, no expression of approval from their contituents. On the other hand, I was recently in a United States Senator's private office and satw a stack of telegrams several inches high on his desk, more than three hundred as I recall it, which had just been received. The statement was made that these were largely duplicated telegrams from the same city and that such a system of attempting to influence legislation was a waste of effort and money. The point that I wish to make is that it is possible to overwork even a good thing, and had an organization. expressed itself, even less forcibly than the repetition of these individual telegrams, the effect would have been far better, since it was easily observed that this method was neither an individual expression or the expression of an organization. The fact that 
our dental profession has not been systematically organized until recently, and the fact that the legislators respond more promptly to an organized effort rather than to an individual appeal, has distinctly worked to our disadvantage in securing anything like satisfactory legislation.

I am fully convinced that the legislator, whether he be representing his ward in his municipality, his country or district in his state, or his district or state in Congress, is fully cognizant of the fact that he owes the position he occu. pies to the support of his constituents and he is therefore usually an 1 quite naturally interestel in serving these to the best of his ability. Contrary to this, we will admit that there are times when we feel as tho those who have been placed in such positions show a dispo. sition to go contrary to what would seem to best meet the requirements. For instance, there are those thus promote 1 who instead of "growing" with the office simply "swell up" in the office. However, this is the exception to the rule and we should be generous enough, at all times, to recognize that there are at least two angles to every question an 1 that the conscientious legislator is confronted with all of this and usually votes in accordance with the preponderance of the evidence submitted. Therefore, it is all the more important that any pending legislation should receive liberal sup. port from all sections of the country, and in this manner the state Dental Society becomes an important factor. Further, the tendency of every profession or vocation is to promote legislation which is frequently classe 1 as more or Iess special and many times there is a distinct selfish motive prompting much of this and it remains for the legislators to weigh the evidence pre. sented and view all of this from its various angles before determining just what is best to do.

The duties and responsibilities of those serving in Congress naturally calls for our best type of citizens and, generally speaking, they are genuinely human and must necessarily be shown that there is merit in the proposed legislation. Also, it is distinctly advantageous when it can be shown that the question under consideration is advocated by a large percentage of those directly associated in the particular phase of any work and that the same has been fully discussed and carefully prepared before endorsement or approval by the organizations advocating the legislation.

One of the most important things to do in connection, with any legislative program, is to have the matter handled thru one central committee or head, which eliminates the possibilites of complicating the situation and confusing the legislators. This Committee should be empowered to act officially upon questions requiring prompt decision in order to best meet developments and promote or conserve, as the case may be, what seems to be for our best interests. Nothing can be more discouraging or disastrous than to have a legislator or committee about ready to take favorable action upon any pending legislation and then to have some outside and unexpected proposition submitted, from a source that should be cooperating, which is not altogether in harmony with the plans under consideration. This gives the man who is only luke warm to the question a most favorable opportunity to throw up his hands and exclaim that it is quite evident that the particular profession or vocation from which the legislation eminated would seem far from being in accord, and therefore a motion to postpone action or attempt to make some compromise frequently results in no action or something that is far from satisfactory.

Some have argued that as a profession we should take the position of first pledging candidates to our cause before election, but I cannot speak too strongly against such a procedure. I maintain 
that the man who will pledge himself to any question, in advance of knowing the full facts, is not worthy of being elected to any position of trust. Further, the man who will obligate himself to one cause, under a moderate amount of pressure or influence, will assume a similar obligation from the other side, assuming that there is at least two sides to every question, in the event that they present a stronger front and center more influence upon him or in the last analysis, promise more support. My position is that when the members of our profession awake to a full appreciation of their duties and responsibilities, not only as dentists but as citizens of the community in which they reside, they will then naturally come in closer touch with men in both public and private affairs to the end that they are better fortified to present a meritorious proposition. Under such conditions they become known as broad minded citizens, with an interest in public affairs generally, and thus their recommendations receive far more weight and consideration. Unfortunately when some members of our profession have been inclined to assume some such responsibilities there is a disposition with others to wholly misunderstand what has prompted such activities and at times some narrow minded and selfish persons have been prompted to be critical instead of commendatory. Thus, the enthusiasm of many a dentist, along the activities which I have outlined, has been thwarted or at least very decidedly modified.

To return to the question of interesting legislators, it would seem to me quite appropriate to systematically take up these questions with your legislators and when this can be done at home, and by those personally acquainted with the said legislator, a greatly stimulated interest frequently results. If this legislator evidences any special interest, either for or against the general question, the person or persons interviewing him should report this to the Legislative Committee in charge in order that they might be fully advised of either promised support or positive opposition. While I am strongly opposed to attempting to obligate men in advance of election, yet I am fully convinced that, as a matter of justness we should, both as individuals and as organizations, express our appreciation and give our support to those who have taken an interest in our legislation.
Further, it is certainly the part of wisdom to maintain in office a man familiar with our needs and who has loyally supported us, rather than take too many chances in changes. I am not attempting to make this a political question, but am willing to view this in the same manner that most of us view the crisis which has been confronting our country recently, that is, we are Americans first and only partisans after all our obligations to our country have been fully discharged. With reference to our professions' attitude toward those who have been our strong supporters in important legislation, we should be appreciative dentists first and only be partisans, which is our inherent right, after our obligations to our friends and loyal supporters have been fully discharged.

Finally, in order to successfully promulgate any legislative program it is necessary for those having this in charge to be thoroly interested in the work and the following quotation is especially appropriate:

"We must live in our work, to do it well; We must dwell in its spirit and bow to its spell;

We must love it and know it to make it count,

We must feel it and trust it before we mount;

We must get from it comfort and pleasure and rest,

We must live in our work if we'd do it best.

And, ah, there is something to gain from it all-

In spite of the shadows and sorrows that fall;

Something of beauty and cheer and content

Out of the struggle, if over it bent

We live in it largely and draw from its beat

The joy and the gladness, the fervor and sweet.

We must live in our work, we must know what it means

To give our whole souls to it-whether it's jeans

Or velvets or satins in which we must toil,

Whether the shop or the mill or the soil,

Whether the green country lane or the mart-

We do the work best when we give it our heart." 